\title{
Characterization of the Mycelial Compatibility Groups and Mating Type Alleles in Populations of Sclerotinia minor in Central China
}

Dan Yang, Jing Zhang, and Mingde Wu, The State Key Laboratory of Agricultural Microbiology and Hubei Key Laboratory of Plant Pathology, Huazhong Agricultural University, Wuhan 430070, China; Weidong Chen, United States Department of Agriculture, Agricultural Research Service, Washington State University, Pullman, WA; and Guoqing Li and Long Yang, The State Key Laboratory of Agricultural Microbiology and Hubei Key Laboratory of Plant Pathology, Huazhong Agricultural University, Wuhan 430070, China

\begin{abstract}
Yang, D., Zhang, J., Wu, M. D., Chen, W. D., Li, G. Q., and Yang, L. 2016. Characterization of the mycelial compatibility groups and mating type alleles in populations of Sclerotinia minor in central China. Plant Dis. 100:2313-2318.

Ninety-five single-sclerotium isolates were obtained from lettuce and weeds in three counties in central China. They were identified belonging to Sclerotinia minor based on colony morphology and the $S$. minor-specific DNA marker. Mycelial compatibility groups (MCGs) and the mating type $(M A T)$ alleles in these isolates were determined using the methods of paired cultures and specific PCR, respectively, and the MCG data were used to calculate Shannon's $H$ index $(H)$ and Simpson index $(S)$, thereby evaluating diversity of $S$. minor. Eight MCGs (MCG1 to MCG8) and two $M A T$ alleles (Inv+, Inv-) were identified in these isolates. Low diversity

was detected for the total 95 isolates $(H=1.748, S=0.786)$. Isolates of different MCGs or with different $M A T$ alleles did not significantly differ $(P>0.05)$ in mycelial growth rate on potato dextrose agar $\left(\mathrm{PDA}, 20^{\circ} \mathrm{C}\right)$ or lesion diameter on lettuce leaves $\left(20^{\circ} \mathrm{C}\right)$, but slightly differed in the number of sclerotia produced on PDA $\left(20^{\circ} \mathrm{C}\right)$. Furthermore, this study reported five new host plants of $S$. minor in China, including Capsella bursapastoris, Oenanthe javanica, Fragaria gracilis, Ranunculus ternatus, and Salvia plebeia, and identified three hypovirulent isolates. These results broaden our understanding about the population biology of $S$. minor.
\end{abstract}

Sclerotinia minor Jagger is a cosmopolitan plant-pathogenic fungus (Abawi and Grogan 1979; Melzer et al. 1997). It is a close relative of S. sclerotiorum (Lib.) de Bary. Both S. minor and S. sclerotiorum can aggressively infect many economically important crops, including lettuce (Lactuca sativa). The resulting Sclerotinia diseases, including lettuce drop and stem rot, usually cause substantial economic losses (Subbarao 1998).

Both S. minor and S. sclerotiorum are homothallic (self-fertile) fungi (Ekins et al. 2006). As in other homothallic ascomycetes, the two idiomorphs of the mating type gene (MAT), namely MAT1-1 and MAT1-2, are connected end-to-end in the genomes of $S$. minor and S. sclerotiorum (Amselem et al. 2011; Chitrampalam and Pryor 2015). Recent studies by Chitrampalam and colleagues (2013), and by Chitrampalam and Pryor (2015) showed that the two fungi have two MAT alleles, namely Inv+ (MAT inversion positive) and Inv(MAT inversion negative). Whether the MAT inversion occurs in other populations of $S$. minor or not remains unknown.

The two Sclerotinia species can form sclerotia, which serve as dormant structures to survive dry and high temperature conditions. Under proper low-temperature conditions, the sclerotia germinate to produce mycelia (myceliogenic germination) or apothecia bearing ascospores (carpogenic germination). The resulting mycelia can directly infect hosts, whereas ascospores (from the apothecia) are generally transmitted to plants by wind, thereby initiating plant infection. Previous observations showed that $S$. minor differs greatly from $S$. sclerotiorum in germination behavior under field conditions. $S$. minor sclerotia usually germinate myceliogenically, and occasionally germinate carpogenically (Abawi and Grogan 1979; Ekins et al. 2002; Hawthorne 1976). On the other hand, S. sclerotiorum sclerotia usually germinate carpogenically, and occasionally germinate myceliogenically (Bolton et al. 2006;

Corresponding author: Long Yang, E-mail: yanglong@mail.hzau.edu.cn

*The $\boldsymbol{e}$-Xtra logo stands for "electronic extra" and indicates that five supplementary figures and four supplementary tables are available online.

Accepted for publication 26 April 2016.

http://dx.doi.org/10.1094/PDIS-12-15-1453-RE

(C) 2016 The American Phytopathological Society
Huang and Dueck 1980). Differences between S. minor and S. sclerotiorum in germination behavior and dispersal of mycelia/ascopsores may result in formation of the populations with different genetic structure. In-depth understanding of the population structure will be helpful for management of diseases caused by these two fungi.

Since the early 1990s, extensive studies have been done to characterize the populations of $S$. sclerotiorum on various host plants around the world (Ahmed et al. 2007; Atallah et al. 2004; Attanayake et al. 2012, 2013; Barari et al. 2010; Carpenter et al. 1999; Clarkson et al. 2013; Durman et al. 2003; Hemmati et al. 2009; Kohn et al. 1991; Lehner et al. 2015; Li et al. 2009; Mandal and Dubey 2012; Sexton and Howlett 2004; Sexton et al. 2006). The methods used in these studies include mycelial compatibility grouping (MCG) and molecular fingerprinting/haplotyping (Kohli and Kohn 1996; Kohn et al. 1991; Mandal and Dubey 2012; Sexton and Howlett 2004; Sirjusingh and Kohn 2001). Initially, populations of S. sclerotiorum from oilseed rape or canola (Brassica napus) were considered to be clonal (Anderson and Kohn 1995), but recent studies showed that S. sclerotiorum populations from several crops such as oilseed rape (B. napus), pea (Pisum sativum), potato (Solanum tuberosum), soybean (Glycine max), and sunflower (Helianthus annuus) have high levels of genetic diversity and showed evidence of recombination, suggesting outcrossing occurs in S. sclerotiorum under natural conditions (Atallah et al. 2004; Attanayake et al. 2012, 2013, 2014; Sexton and Howlett 2004; Sexton et al. 2006).

However, limited information is available about the population characteristics in S. minor. Studies by Cubeta et al. (2001), Melzer and Boland (1996), and Wu and Subbarao $(2001,2006)$ showed that $S$. minor exhibits mycelial incompatibility similar to that in S. sclerotiorum. Wu and Subbarao (2006) studied MCG diversity of S. minor on lettuce in Salinas, San Joaquin, and Santa Maria valleys in California, United States. They found that there were at least 23 MCGs in the three sampled regions. Most MCGs consisted of only one or two isolates each. Four MCGs dominated the populations and accounted for $91.4 \%$ of the total isolates $(n=243)$, and one of the four MCGs was the most prevalent and found in all the three investigated regions, accounting for $49.8 \%$ of the total isolates ( $\mathrm{Wu}$ and Subbarao 2006). The MCG diversity is considerably lower than that found in S. sclerotiorum. Garrido and colleagues (2011) used inter simple sequence repeat (ISSR) fingerprinting to evaluate genetic diversity and 
structure of the $S$. minor isolates from peanut in Oklahoma, United States. They found that the genetic differences among the sampled $S$. minor isolates reached significant level $(P=0.001)$ based on the 38 polymorphic DNA bands generated by the ISSR markers (Garrido et al. 2011).

$S$. minor has been reported to infect lettuce and Chinese cabbage (Brassica rapa subsp. pekinensis) in central China (Li et al. 1994; Lyu et al. 2014), and sunflower in northern China (Li et al. 2016; Wen et al. 1995). However, little is known about genetic diversity and population structure of this fungus in China. Therefore, this study was conducted to fulfill the following two objectives: i) to identify the MCGs and MAT alleles (Inv+ and Inv-) in S. minor on lettuce in central China; and ii) to determine whether there are differences among MCGs or among isolates with different MAT alleles in mycelial growth rate, sclerotial, formation and aggressiveness.

\section{Materials and Methods}

Fungal isolates. A total of 98 isolates of $S$. minor were used in this study (Table 1). Ninety-five single-sclerotium isolates were obtained from 95 sclerotial samples collected from 13 fields (six oilseed rape fields and seven lettuce fields) in three counties (Dangyang, Lichuan, and Xianning) in Hubei Province of China (Supplementary Fig. S1, Table 1, Supplementary Table S1). The $S$. minor isolates from a county were considered a population. The sampled fields in each county were spaced by 2 to $10 \mathrm{~km}$ and the sampled plants (all at the seedling stage) in each field were spaced by at least $20 \mathrm{~m}(20$ to $50 \mathrm{~m}$ ). Sclerotia collected from a single diseased plant were regarded as one sample. They were surface-sterilized with $\mathrm{HgCl}_{2}$ solution and placed on acidified potato dextrose agar (PDA), and the colonies from the sclerotia were hyphal tipped to obtain pure cultures. The remaining three isolates of $S$. minor (W1, W26 and P13) used in this study were kindly provided by Dr. Barbara Shew of North Carolina State University in the United States. They were isolated from Cyperus sp. (Cyperaceae), Lamium sp. (Lamiaceae), and Arachis hypogaeae (peanut), respectively, in North Carolina (Table 1).

Species identification of the isolates. The fungal isolates were identified to species based on cultural and morphological characteristics on PDA $\left(20^{\circ} \mathrm{C}\right)$, and on the $S$. minor-specific DNA marker (264 bp long in laccase gene 2) generated by PCR using the primer pair SMLcc2F/SMLcc2R (Abd-Elmagid et al. 2013). For observation of the cultural and morphological characteristics, mycelial agar plugs ( $5 \mathrm{~mm}$ diameter) of each isolate from the edge of an actively growing PDA culture were transferred to petri dishes $(9 \mathrm{~cm}$ diameter) each containing $20 \mathrm{ml}$ PDA, one agar plug per dish, and five dishes (replicates) for each isolate. The dishes were incubated at $20^{\circ} \mathrm{C}$ under the lighting regime of $12 / 12 \mathrm{~h}$ light/dark. Colony diameter in each dish was measured at 24 and $48 \mathrm{~h}$ and the data were used to calculate radial growth rate $(\mathrm{cm} /$ day). The cultures were further incubated for 30 days and the sclerotia in each dish were counted.

Confirmation of new host plants. Among the 11 sampled plant species, six plant species, including B. rapa ssp. pekinensis (Chinese cabbage), Conyza canadensis, L. sativa (lettuce), P. sativum (pea), Plantago sp., and Trifolium repens (white clover), have been recorded as hosts of S. minor (Hollowell et al. 2003; Lyu et al. 2014; Melzer et al. 1997). The remaining five weed species, including Capsella bursa-pastoris, Oenanthe javanica, Fragaria gracilis, Ranunculus ternatus, and Salvia plebeia, have not been reported as hosts of $S$. minor, so pathogenicity tests were conducted. Wild plants of each species at the rosette stage were uprooted and transplanted in pots $(12 \times 8 \mathrm{~cm}$, diameter $\times$ height $)$ containing organic culture mix (Zhengjiang Peilei Organic Manure Manufacturing Co. Ltd., Zheng Jiang City, Jiangsu Province, China), with one plant per pot and six pots for each plant species. The plants were maintained in a growth chamber $\left(20^{\circ} \mathrm{C}\right)$ under the lighting regime of $12 / 12 \mathrm{~h} \mathrm{light/dark}$ for 15 days. For each plant species, three plants were inoculated with isolate XN04 of $S$. minor by placing the mycelial agar plugs $(5 \mathrm{~mm}$ diameter) from 2-day-old PDA cultures on leaves in the center of each plant, one agar plug on each leaf, and five leaves for each plant. The remaining three plants were inoculated with agar plugs removed from fresh PDA in the same fashion and were treated as controls. The plants were placed in a mist chamber $\left(100 \%\right.$ relative humidity) at $20^{\circ} \mathrm{C}$ under 12/12 h light/dark for 5 days and observed for symptoms.

For reisolation of the fungus, three symptomatic leaves were randomly sampled and detached from each $S$. minor-inoculated plant. The tissue at the lesion margin area on each leaf was cut into small pieces (approximately $3 \mathrm{~mm}$ in diameter), surface-sterilized with $\mathrm{NaClO}$, and placed on lactic acid-amended PDA in a petri dish, with three leaf pieces per dish and three dishes for each plant species. The cultures were incubated at $20^{\circ} \mathrm{C}$ in dark for 2 days. The resulting colonies around the leaf pieces were individually transferred to fresh PDA, one colony per dish. The cultures were incubated at $20^{\circ} \mathrm{C}$ in dark for 30 days and observed for growth and sclerotial formation. This experiment was repeated once.

Aggressiveness assessment. Fully expanded leaves of lettuce cv. Siji with the average size of $25 \times 7 \mathrm{~cm}$ (length $\times$ width) were excised from 80-day-old plants and placed on water-moisturized paper towels in plastic trays $(56 \times 38 \times 8 \mathrm{~cm}$, length $\times$ width $\times$ depth $)$, nine leaves per tray. Nine mycelial agar plugs $(5 \mathrm{~mm}$ diameter) were removed from the colony margin of a PDA culture of an $S$. minor isolate and placed on three leaves, three agar plugs per leaf (spaced by about $8 \mathrm{~cm}$ ). Meanwhile, three lettuce leaves inoculated with agar plugs from fresh PDA were treated as controls. The trays were individually covered with 0.1-mm-thick transparent plastic films (Jiangmen Xing Feng Development Co. Ltd., Jiangmen City, Guangdong Province, China)

Table 1. Origin of the isolates of Sclerotinia minor collected from Dangyang, Lichuan, and Xianning counties in Hubei Province of China, and from North Carolina in the United States

\begin{tabular}{|c|c|c|c|}
\hline Region $^{\mathrm{z}}$ & Host species (family) & Collection time (Year-month) & No. isolates \\
\hline Dangyang (1 field) & Plantago sp. (Plantaginaceae) & $2012-03$ & 3 \\
\hline Lichuan (7 fields) & Lactuca sativa (Compositae) & 2012-05 & 53 \\
\hline \multirow[t]{10}{*}{ Xianning (5 fields) } & Brassica rapa ssp. pekinensis (Brassicaceae) & 2012-03 & 9 \\
\hline & Capsella bursa-pastoris (Brassicaceae) & $2012-03$ & 2 \\
\hline & Conyza canadnsis (Compositae) & 2011-10 & 4 \\
\hline & Lactuca sativa (Compositae) & 2009-05 & 3 \\
\hline & Oenanthe javanica (Umbelliferae) & 2012-03 & 4 \\
\hline & Fragaria gracilis (Rosaceae) & 2012-03 & 3 \\
\hline & Ranunculus ternatus (Ranunculaceae) & 2012-03 & 4 \\
\hline & Pisum sativum (Leguminosae) & 2012-03 & 2 \\
\hline & Trifolium repens (Leguminosae) & $2012-03$ & 2 \\
\hline & Salvia plebeia (Labiatae) & 2012-03 & 6 \\
\hline \multirow[t]{3}{*}{ North Carolina (U.S.A.) } & Cyperus sp. (Cyperaceae) & 2000 & 1 (Isolate W1) \\
\hline & Lamium sp. (Lamiaceae) & 2002 & 1 (Isolate W26) \\
\hline & Arachis hypogaea (Leguminosae) & 1998 & 1 (Isolate P13) \\
\hline Total & 14 plant species ( 9 families) & & 98 \\
\hline
\end{tabular}

${ }^{\mathrm{z}}$ Geographical location: Dangyang County at $111.78^{\circ} \mathrm{E} / 30.82^{\circ} \mathrm{N}$, Lichuan County at $108.93^{\circ} \mathrm{E} / 30.30^{\circ} \mathrm{N}$, Xianning County at $114.32^{\circ} \mathrm{E} / 29.85^{\circ} \mathrm{N}$. 
to maintain high humidity and in the chamber at $20^{\circ} \mathrm{C}$ under the lighting regime of $12 / 12 \mathrm{~h}$ light/dark. Lesion diameters were measured $48 \mathrm{~h}$ post inoculation (hpi). This experiment was repeated once.

Mycelial compatibility grouping. Three mycelial agar plugs of $S$. minor were placed in an equilateral triangle $(2 \mathrm{~cm}$ apart between two agar plugs) on PDA in a petri dish (9 $\mathrm{cm}$ diameter). Two of the three mycelial agar plugs were from the same isolate and the other agar plug was of a different isolate to test mycelial compatibility between the two isolates. The two agar plugs from the same isolate was for testing self-compatibility. The 95 Chinese isolates of $S$. minor were tested pairwise in all possible combinations with three replicates for each combination. All the triple cultures were incubated at $20^{\circ} \mathrm{C}$ in dark for 14 days and the three colonies in each dish were examined for compatible or incompatible interactions with the criteria described by $\mathrm{Wu}$ and Subbarao $(2001,2006)$.

To test mycelial compatibility of the $S$. minor isolates from central China with the three American isolates (W1, W26, and P13), a total of 15 isolates from central China representing eight MCGs (14 isolates for MCG1 to MCG7 with two isolates for each MCG and one isolate for MCG8) were selected and individually paired with each of the three American isolates. They were paired on PDA using the same method described above.

Typing of the MAT alleles. The $S$. minor isolates were incubated on sterilized cellophane films in PDA dishes at $20^{\circ} \mathrm{C}$ for 3 to 4 days. The mycelial mats for each isolate were harvested from the cellophane films and ground in liquid $\mathrm{N}_{2}$ to fine powder, which was subsequently used for DNA extraction using the CTAB method (Möller et al. 1992). The DNA was dissolved in sterilized $d_{d d H_{2}} \mathrm{O}$ and the DNA concentration in the solution was determined in NANODROP 2000 UV-Vis spectrophotometer (Thermo Fisher Scientific Inc., Wilmington, DE, U.S.A.).

The MAT alleles (Inv-, Inv+, heterokaryon) in $S$. minor were detected by PCR using the primer pairs MAT1-1-F/MAT1-1-R (Inv-) and Type-IIF/Type-IIR (Inv+) reported in the previous study by Chitrampalam and Pryor (2015). Amplification of the internal transcribed spacer (ITS) of the ribosomal DNA with the primer pair ITS1/ITS4 (White et al. 1990) was used as control to check for DNA quality. The PCR was done in Bio-RAD S1000 Thermal Cycler using the program described by Chitrampalam and Pryor (2015). The resulting PCR fragments $(539,674$, and 1,348 bp for ITS, Inv-, and Inv+, respectively), were detected by agarose gel electrophoresis. The DNA fragments amplified from isolates XN01 (Inv-), XN02 (Inv-), DY02 (Inv+), LC41 (Inv+), XN19 (heterokaryon), and XN34 (heterokaryon) were individually cloned in E. coli using the pMD18-T vector (TaKaRa Biotechnology Co. Ltd., Dalian, China) and sequenced. The resulting DNA sequences were aligned with the corresponding DNA sequences for Inv- and Inv+ in isolates SM1 (Inv-) and SM24 (Inv+) of S. minor (Chitrampalam and Pryor 2015).

Nine $S$. minor isolates, including three Inv- isolates (XN01, XN02, XN03), three Inv+ isolates (DY02, XN04, LC41), and three heterokaryon isolates (XN19, XN34, LC19) were selected to test the stability of the MAT alleles. They were incubated at $20^{\circ} \mathrm{C}$ on PDA and one of the 2-day-old cultures for each isolate was randomly chosen to do single-hyphal tip (SHT) isolation using a fine needle under a stereo microscope. The single-hyphal tips were individually transferred to PDA plates, one hyphal tip per plate, and the plates were placed in an incubator $\left(20^{\circ} \mathrm{C}\right)$ for 4 days. The resulting cultures were subjected to another round of SHT isolation. Nine SHT isolates (one from each parental isolate) were finally obtained. The MAT allele(s) in the SHT isolates as well as in the parents were determined by PCR using the primers mentioned above.

Detection of dsRNA. Isolate LC22 of $S$. minor was cultured for 2 days on cellophane membrane films placed on PDA $\left(20^{\circ} \mathrm{C}\right)$. Mycelial mats were harvested for extraction of dsRNA using the procedures described in our previous study (Wu et al. 2007). The dsRNA in the mycelial extracts was detected by electrophoresis in $1 \%(\mathrm{w} / \mathrm{v})$ agarose gel. The dsRNA nature was further confirmed based on its resistance to S1 nuclease and DNase I (Wu et al. 2007).

Data analysis. Data for mycelial growth rate in culture, number of sclerotia produced on PDA, and lesion diameter on lettuce leaves were analyzed using the procedure ANOVA (analysis of variance) in SAS software (SAS Institute, Cary, NC, U.S.A., v. 8.0, 1999). Mean values of each parameter for the $S$. minor isolates of different MCGs or with different MAT alleles were separated using StudentNewman-Keul's (SNK) multiple comparison test at $\alpha=0.05$. MCG8 was not included in the analysis, as only one isolate (LC36) belonged to this MCG. Likewise, two MCG5 isolates, namely LC22 and LC38, were also excluded in the analysis, as they were severely debilitated in mycelial growth and aggressiveness.

\section{Results}

Identification of $S$. minor from different host plants. On PDA at $20^{\circ} \mathrm{C}, 92$ isolates from central China (accounting for $96.8 \%$ of the total 95 isolates) grew rapidly with average growth rates ranging from $1.07 \pm 0.06$ to $1.99 \pm 0.05 \mathrm{~cm} /$ day (means \pm standard deviation, S.D.), whereas the remaining three isolates, namely LC22, LC38 (both from

Table 2. Mycelial compatibility groups (MCGs) and MCG-related diversity indices in Sclerotinia minor

\begin{tabular}{|c|c|c|c|c|c|c|c|c|c|c|c|}
\hline \multirow[b]{2}{*}{ Population } & \multicolumn{9}{|c|}{ Number of isolates } & \multirow[b]{2}{*}{ Shannon's $H$ index ${ }^{y}$} & \multirow[b]{2}{*}{ Simpson index ${ }^{z}$} \\
\hline & MCG1 & MCG2 & MCG3 & MCG4 & MCG5 & MCG6 & MCG7 & MCG8 & Subtotal & & \\
\hline Dangyang & 1 & 2 & 0 & 0 & 0 & 0 & 0 & 0 & 3 & 0.636 & 0.444 \\
\hline Lichuan & 5 & 26 & 10 & 0 & 6 & 0 & 5 & 1 & 53 & 1.431 & 0.692 \\
\hline Xianning & 23 & 0 & 0 & 10 & 0 & 6 & 0 & 0 & 39 & 0.948 & 0.563 \\
\hline Total & 29 & 28 & 10 & 10 & 6 & 6 & 5 & 1 & 95 & 1.748 & 0.786 \\
\hline
\end{tabular}

y Shannon's $H$ index $=-\Sigma[(f i) \ln (f i)]$.

${ }^{\mathrm{z}}$ Simpson index $=1-$ dominance $=1-\Sigma\left[(f i)^{2}\right]$, where $f i$ is the frequency of isolates in the $i$ th MCG.

Table 3. Mycelial growth rates and number of sclerotia produced by the Sclerotinia minor isolates belonging to different mycelial compatibility groups (MCGs) on PDA, and lesion diameters on detached lettuce leaves (all at $20^{\circ} \mathrm{C}$ )

\begin{tabular}{lcccc}
\hline MCG & ${\text { Number of } \text { isolates }^{\mathbf{y}}}$ & Growth rate $(\mathbf{c m} / \mathbf{d a y} \pm$ S.D. $)$ & Number of sclerotia (No. per dish \pm S.D.) & Lesion diameter $(\mathbf{c m} \pm$ S.D.) \\
\hline MCG1 & 29 & $1.53 \pm 0.25 \mathrm{a}^{\mathrm{z}}$ & $1387 \pm 280 \mathrm{ab}^{\mathrm{z}}$ & $3.58 \pm 0.54 \mathrm{a}^{\mathrm{z}}$ \\
MCG2 & 28 & $1.42 \pm 0.22 \mathrm{a}$ & $1562 \pm 215 \mathrm{ab}$ & $3.28 \pm 0.38 \mathrm{a}$ \\
MCG3 & 10 & $1.41 \pm 0.25 \mathrm{a}$ & $1640 \pm 189 \mathrm{a}$ & $3.37 \pm 0.42 \mathrm{a}$ \\
MCG4 & 10 & $1.49 \pm 0.20 \mathrm{a}$ & $1483 \pm 519 \mathrm{ab}$ & $3.70 \pm 0.63 \mathrm{a}$ \\
MCG5 & 4 & $1.68 \pm 0.12 \mathrm{a}$ & $1767 \pm 252 \mathrm{a}$ & $3.05 \pm 0.68 \mathrm{a}$ \\
MCG6 & 6 & $1.41 \pm 0.36 \mathrm{a}$ & $1221 \pm 392 \mathrm{~b}$ & $3.17 \pm 0.78 \mathrm{a}$ \\
MCG7 & 5 & $1.40 \pm 0.28 \mathrm{a}$ & $1772 \pm 170 \mathrm{a}$ & $2.86 \pm 1.25 \mathrm{a}$ \\
\hline
\end{tabular}

y Isolates LC22 (MCG5), LC36 (MCG8) and LC38 (MCG5) were not included in the analysis.

${ }^{\mathrm{z}}$ Means \pm S.D. within each column followed by different letters are significantly different according to the multiple comparison test $(\mathrm{SNK})(P<0.05)$. 
lettuce in Lichuan County), and XN05 (from Salvia plebeia in Xianning County), grew slowly with the average growth rates of $0.68 \pm$ $0.32,0.92 \pm 0.08$, and $0.90 \pm 0.20 \mathrm{~cm} /$ day (means \pm S.D.), respectively. After incubation for 30 days, all 95 Chinese isolates produced abundant black sclerotia in the PDA cultures. Meanwhile, a DNA fragment 264 bp in size was amplified in all the 95 Chinese isolates, as well as in the three American isolates (W1, W26, and P13), using the S. minor-specific primer pair SMLcc2F/SMLcc2R, which targets to the laccase gene 2 (Abd-Elmagid et al. 2013). This result confirms that all the 95 sclerotia-forming isolates from central China belong to $S$. minor.

Confirmation of new host plants. After incubation at $20^{\circ} \mathrm{C}$ for 5 days, the leaves of each suspected host plant (C. bursa-pastoris, $O$. javanica, $F$. gracilis, $R$. ternatus, or $S$. plebeia) inoculated with $S$. minor formed water-soaked leaf lesions around the agar plugs, whereas the leaves inoculated with fresh PDA remained healthy. A fungus was reisolated from the infected leaf tissues. On PDA, it grew rapidly and formed tiny sclerotia, but did not form any spores. The colony morphology appeared similar to that of $S$. minor (data not shown). These results confirm that are the hosts of $S$. minor.

Aggressiveness. All 95 isolates of $S$. minor infected lettuce leaves after incubation at $20^{\circ} \mathrm{C}$ for $48 \mathrm{~h}$. Ninety-two isolates (accounting for $96.8 \%$ of the total isolates) were highly aggressive, with the average leaf lesion diameters ranging from $2.22 \pm 0.07$ to $4.25 \pm 0.26 \mathrm{~cm}$ (means \pm S.D.). The remaining three isolates (accounting for $3.2 \%$ of the total isolates), namely LC18, LC22, and LC38 (all from lettuce in Lichuan County), were weakly aggressive with the average leaf lesion diameters of $1.07 \pm 0.08,0.77 \pm 0.21$, and $0.58 \pm 0.13 \mathrm{~cm}$ (means \pm S.D.), respectively.

Mycelial compatibility groups. In the MCG tests, all S. minor isolates were self-compatible. MCG pairing grouped the 95 isolates of $S$. minor from central China into eight MCGs (MCG1 to MCG8). The three American isolates were not compatible with one another, nor with any of the 15 selected isolates representing eight MCGs from central China, thus forming three single-isolate MCGs. All incompatible reactions between two isolates of different MCGs were characterized by formation of a whitish or light-brownish barrage zone (Supplementary Fig. S2) between two colonies except the pairings with the American isolate P13. The incompatible reaction of isolate P13 with the other isolates from central China or the other two American isolates was characterized by formation of a dark-brownish barrage zone between the two colonies. Therefore, it may represent a unique incompatible interaction pattern.

MCG1 and MCG2 were the most prevalent, comprising 29 and 28 isolates (accounting for 30.5 and $29.5 \%$ of the total 95 isolates), respectively. In contrast, MCG8 was the least prevalent, comprising only one isolate (accounting for $1.1 \%$ of the total isolates) in Lichuan.

Table 4. Proportion of the mating type alleles (Inv-, Inv+, and heterokaryon) in different populations of Sclerotinia minor

\begin{tabular}{lcccr}
\hline & \multicolumn{3}{c}{ Number of isolates (percentage) } \\
\cline { 2 - 5 } Population $^{\mathbf{z}}$ & $\boldsymbol{M A T}$ Inv- & $\boldsymbol{M A T}$ Inv+ & $\boldsymbol{M A T}$ Heterokaryon & Subtotal \\
\hline DY & $0(0 \%)$ & $3(100 \%)$ & $0(0 \%)$ & $3(100 \%)$ \\
LC & $1(2 \%)$ & $39(74 \%)$ & $13(24 \%)$ & $53(100 \%)$ \\
XN & $3(8 \%)$ & $14(36 \%)$ & $22(56 \%)$ & $39(100 \%)$ \\
Total & $4(4 \%)$ & $56(59 \%)$ & $35(37 \%)$ & $95(100 \%)$ \\
\hline
\end{tabular}

${ }^{\mathrm{z}} \mathrm{DY}=$ Dangyang; $\mathrm{LC}=$ Lichuan; $\mathrm{XN}=$ Xianning.
The remaining five MCGs (MCG3 to MCG7) were the moderately prevalent, comprising $10,10,6,6$, and 5 isolates accounting for $10.5,10.5,6.3,6.3$, and $5.3 \%$ of the total isolates, respectively.

Both MCG1 and MCG2 had a wide geographical distribution. MCG1 occurred in seven fields in Dangyang, Lichuan, and Xianning counties (Table 2). MCG2 also occurred in seven fields in Dangyang and Lichuan counties, but did not occur in Xianning County. On the other hand, the remaining six MCGs had a limited geographical distribution. MCG3, MCG5, MCG7, and MCG8 occurred only in Lichuan County, whereas MCG4 and MCG6 only occurred in Xianning County.

Shannon's $H$ index $(H)$ and Simpson index $(S)$ for the total 95 isolates and for the isolates from each county were calculated based on the MCG data. For the total 95 isolates, Shannon's $H$ index was 1.748 and the Simpson index was 0.786 (Table 2). For the isolates from the three counties, both indices differed greatly (Table 2). Relatively, the diversity level was high in Lichuan $(H=1.431, S=0.692)$ and moderate in Xianning $(H=0.948, S=0.563)$, but was low in Danyang $(H=0.636$, $S=0.444)$, possibly due to the limited number of isolates $(n=3)$.

The isolates of seven MCGs (MCG1 to MCG7) were compared for differences in mycelial growth rate and number of sclerotia on PDA $\left(20^{\circ} \mathrm{C}\right)$, and leaf lesion diameters on lettuce $\left(20^{\circ} \mathrm{C}, 48 \mathrm{hpi}\right)$. Results showed that the seven MCGs did not significantly differ in mycelial growth rates $(P=0.3112)$ and lesion diameters $(P=0.0427)$, but significantly differed in number of sclerotia $(P=0.0039)$ (Table 3 , Supplementary Table S2). MCG3, MCG5, and MCG7 had significantly higher number of sclerotia than that of MCG6, whereas the remaining three MCGs did not significantly differ (Table 3).

MAT alleles. Using the specific PCR primers MAT1-1-F/MAT11-R and Type-IIF/Type-IIR (Chitrampalam and Pryor 2015), two MAT alleles, Inv- (with a 674-bp DNA band) and Inv+ (with a 1,348-bp DNA band), were detected in $S$. minor (Supplementary Figs. S3 and S4). The DNA sequences for Inv- and Inv+ obtained in this study were $99 \%$ identical to the corresponding DNA sequences reported by Chitrampalam and Pryor (2015). Based on the $M A T$ alleles, the 95 isolates of $S$. minor from central China were classified into three groups, Inv-, Inv+, and heterokaryon (Inv- plus Inv+), which accommodated 4, 56, and 35 isolates (accounting for 4,59 , and $37 \%$ of the total 95 isolates), respectively (Table 4). Inv+ was detected in the isolates collected from all the three counties with the frequencies of 36, 74, and 100\% in Xianning, Lichuan, and Dangyang, respectively. Moreover, we found that the nine single-hypha-tip derivatives had the same MAT alleles as their parent (Supplementary Table S3), thus confirming that the MAT alleles in $S$. minor were quite stable during mycelial subculturings (e.g., through mitotic division).

Additionally, the $S$. minor isolates of different MAT groups were compared for differences in mycelial growth rate and number of sclerotia on PDA, and lesion diameter on lettuce leaves. Results showed that the three groups did not significantly differ in mycelial growth rate $(P=0.3328)$ and lesion diameter $(P=0.4532)$, but significantly differed in number of sclerotia $(P=0.0008)$ (Table 5, Supplementary Table S4). The Inv- isolates had significantly higher number of sclerotia than the isolates in Inv+ and heterokaryon (Table 5).

Detection of dsRNA. A segment of dsRNA was consistently detected in mycelia of the hypovirulent isolate LC22 of S. minor (Supplementary Fig. S5). The segment was confirmed to be dsRNA, as it was resistant to digestion by $\mathrm{S} 1$ nuclease and DNase I. The size of the dsRNA fragment was between 9.4 and $23.1 \mathrm{~kb}$ as indicated by the DNA marker.

Table 5. Mycelial growth rates and number of sclerotia on PDA and lesion diameters caused by the Sclerotinia minor isolates with different MAT alleles (all at $\left.20^{\circ} \mathrm{C}\right)$

\begin{tabular}{lcccc}
\hline $\boldsymbol{M A T}$ allele $^{\mathbf{x}}$ & Number of isolates $^{\mathbf{y}}$ & Growth rate $(\mathbf{c m} / \mathbf{d a y} \pm \text { S.D. })^{\text {Number of sclerotia (No./dish } \pm \text { S.D.) }}$ & Lesion diameter $(\mathbf{c m} \pm$ S.D. $)$ \\
\hline Inv- & 4 & $1.31 \pm 0.15 \mathrm{a}^{\mathrm{z}}$ & $1,853 \pm 334 \mathrm{a}^{\mathrm{z}}$ & $3.10 \pm 0.45 \mathrm{a}^{\mathrm{z}}$ \\
Inv+ & 54 & $1.47 \pm 0.24 \mathrm{a}$ & $1,568 \pm 310 \mathrm{~b}$ & $3.43 \pm 0.52 \mathrm{a}$ \\
Heterokaryon & 35 & $1.50 \pm 0.27 \mathrm{a}$ & $1,369 \pm 313 \mathrm{~b}$ & $3.37 \pm 0.71 \mathrm{a}$ \\
\hline
\end{tabular}

x The three types (Inv-, Inv+, and Heterokaryon) indicate MAT-inversion negative, MAT-inversion positive, and heterokaryon, respectively.

y Isolates LC22 (MCG5), LC36 (MCG8), and LC38 (MCG5) were not included in the analysis.

${ }^{\mathrm{z}}$ Means \pm S.D. within each column followed by different letters are significantly different according to the multiple comparison test $(\mathrm{SNK})(P<0.05)$. 


\section{Discussion}

This study reported five weed plants, namely C. bursa-pastoris, $O$. javanica, F. gracilis, $R$. ternatus, and S. plebeian, as newlyreported hosts of $S$. minor. These plant species, as well as other weed plants (Table 1), commonly occur in fields grown with lettuce, an important host of $S$. minor, in Hubei Province of central China. We found that the $S$. minor isolates from weed plants were highly aggressive in infection of lettuce leaves, suggesting that $S$. minor may have no specificity on the investigated weeds and lettuce. It appears that proper control of weeds in lettuce fields may help to control lettuce drop caused by $S$. minor.

Like $S$. sclerotiorum, the aggressiveness of $S$. minor can be attenuated by some extracellular elements, such as mycoviruses. Melzer and Boland (1996) reported three slow-growing hypovirulent isolates of $S$. minor on lettuce in Canada. Transmissible dsRNA elements were detected in the hypovirulent isolates of $S$. minor according to Melzer and Boland (1996). They also found that the hypovirulent isolates of $S$. minor can be potentially used to control virulent isolates of $S$. minor by attenuating aggressiveness of virulent isolates of through transmission of the dsRNA elements (Melzer and Boland 1996). In this study, we identified three $S$. minor isolates with low aggressiveness. Of the three isolates, LC22 grew slowly on PDA at $20^{\circ} \mathrm{C}$. It harbored a dsRNA element, which might be responsible for reduced growth rate and low aggressiveness of isolate LC22. Further studies are necessary to characterize the nature of the dsRNA element in isolate LC22 and to evaluate the biocontrol potential of this isolate against virulent $S$. minor.

To our knowledge, this is the first study to characterize the MCGs of $S$. minor isolates from China. The $95 \mathrm{~S}$. minor isolates from central China were grouped into eight MCGs in this study (Table 2). The result confirmed previous studies about existence of different MCGs in S. minor (Cubeta et al. 2001; Melzer and Boland 1996; Wu and Subbarao 2001, 2006). We also found that the American isolate P13 of S. minor formed a dark-brownish barrage line in the interaction zone between two incompatible colonies with all the other tested $S$. minor isolates from China and the United States, whereas the remaining isolates of different MCGs formed a whitish or light-brownish barrage line in the interaction zone between two colonies. Therefore, isolate P13 may represent a unique MCG in S. minor. So far, we have not found this MCG in China. Whether or not it exists in other geographical areas in China (e.g., northern China) remains unknown and needs further study.

Wu and Subbarao (2006) compared MCG diversity of S. minor and S. sclerotiorum on lettuce in Salinas and San Joaquin valleys in California. They found that in both regions, the MCG diversity level of S. minor was lower than that of S. sclerotiorum. For example, at the Salinas location, the $S$. minor population had Shannon's $H$ index of 1.557 and Simpson index of 0.697. The values were lower than those for $S$. sclerotiorum $(H=2.587, S=0.861)$. Similar results were also found at the San Joaquin location (Wu and Subbarao 2006). The MCG diversity level of S. minor in central China found in this study appears similar to that of $S$. minor in the western United States (Wu and Subbarao 2006). Although we did not directly compare $S$. minor with $S$. sclerotiorum in this study, the diversity indices $(H=1.748, S=0.786)$ in the $95 S$. minor isolates from central China (Table 2) were generally lower than those reported for S. sclerotiorum in China (Li et al. 2009) as well as in the United States (Attanayake et al. 2013; Wu and Subbarao 2006).

Chitrampalam and colleagues (2013) first reported inversion of the $M A T$ locus (Inv+) in S. sclerotiorum. They also found that MAT inversion does not affect sexual reproduction by this fungus, as the inversion process possibly occurs during meiosis in sexual reproduction (Chitrampalam et al. 2013). Later, Chitrampalam and Pryor (2015) showed that MAT inversion also occurs in $S$. minor. They found that based on the MAT alleles, 38 isolates of $S$. minor from Arizona, U.S.A., could be grouped into three MAT genotypes, namely Inv+, Inv-, and heterokaryon (Inv+ plus Inv-), which comprised 3, 19, and 16 isolates (accounting for 8,50 , and $42 \%$ of the total investigated isolates), respectively (Chitrampalam and Pryor 2015). In the present study, we detected MAT inversion in $S$. minor from central China and three genotypes were grouped in the 95 isolates (Table 4). This result provides additional support for the existence of $M A T$ inversion and MAT heterokaryon in S. minor.

Chitrampalam and colleagues (2013) reported that MAT inversion in S. sclerotiorum may occur in sexual reproduction. Two lines of evidence support this speculation. The first evidence is that the $M A T$-inversion trait segregates at a ratio close to $1: 1$ in ascospore progenies of $S$. sclerotiorum regardless of whether the parent is Invor Inv+. The second evidence is that the Inv+ and Inv- isolates in the natural populations of S. sclerotiorum in California and Nebraska occurred at a ratio also close to 1:1 (Chitrampalam et al. 2013). S. minor might be similar to $S$. sclerotiorum in generation of MAT inversion. Chitrampalam and Pryor (2015) reported that the ratio of Inv+ and Inv-isolates of $S$. minor in Arizona was 6.3:1 $(n=38)$. In this study, we found that the ratio of the Inv+ and Inv- isolates of $S$. minor in central China was 14:1 $(n=95)$ (Table 4). Differences between S. minor and S. sclerotiorum in ratio of Inv+ and Inv- isolates might be caused by different sclerotial germination behaviors in the two fungi, as the $M A T$ inversion generates through sexual reproduction (e.g., carpogenic germination). Higher percentage of Inv+ isolates (56.0\% of the total 95 isolates) in central China than that in Arizona (7.9\%) implies that $S$. minor in central China may undergo sexual reproduction more frequently than that in United States. Further studies to determine segregation of Inv+ and Inv- in ascospore progenies of $S$. minor and to characterize MAT inversion in other populations of $S$. minor in the two countries are warranted.

Statistical analysis indicated that the Inv-isolates had significantly higher number of sclerotia than the isolates with Inv+ and heterokaryon (Table 5). It is hard to explain this phenomenon. The possible reason may lie in the limited number of Inv- isolates used in this study. Further studies using more Inv- isolates are warranted to determine the relationship between the MAT alleles and number of sclerotia in $S$. minor.

\section{Acknowledgments}

This study was financially supported by the Fundamental Research Funds for the Central Universities (Grant No. 2662015PY040), the National Natural Science Foundation of China (Grant Nos. 31272084, 31471813), and the earmarked fund for China Agriculture Research System (Grant No. CARS-13). Kind appreciations are due to Dr. Barbara Shew of North Carolina State University for providing S. minor isolates.

\section{Literature Cited}

Abawi, G. S., and Grogan, R. G. 1979. Epidemiology of diseases caused by Sclerotinia species. Phytopathology 69:899-904.

Abd-Elmagid, A., Garrido, P. A., Hunger, R., Lyles, J. L., Mansfield, M. A., Gugino, B. K., Smith, D. L., Melouk, H. A., and Garzon, C. D. 2013. Discriminatory simplex and multiplex PCR for four species of the genus Sclerotinia. J. Microbiol. Methods 92:293-300.

Ahmed, N., Iqbal, M., Iqbal, U., and Rauf, A. 2007. Morphological variability and mycelial compatibility among the isolates of Sclerotinia sclerotiorum associated with stem rot of chickpea. Mycopathologia 5:11-15.

Amselem, J., Cuomo, C. A., van Kan, J. A. L., Viaud, M., Benito, E. P., Couloux, A., Coutinho, P. M., de Vries, R. P., Dyer, P. S., Fillinger, S., Fournier, E., Gout, L., Hahn, M., Kohn, L., Lapalu, N., Plummer, K. M., Pradier, J.-M., Quévillon, E., Sharon, A., Simon, A., ten Have, A., Tudzynski, B., Tudzynski, P., Wincker, P., Andrew, M., Anthouard, V., Beever, R. E., Beffa, R., Benoit, I., Bouzid, O., Brault, B., Chen, Z. H., Choquer, M., Collémare, J., Cotton, P., Danchin, E. G., Da Silva, C., Gautier, A., Giraud, C., Giraud, T., Gonzalez, C., Grossetete, S., Güldener, U., Henrissat, B., Howlett, B. J., Kodira, C., Kretschmer, M., Lappartient, A., Leroch, M., Levis, C., Mauceli, E., Neuvéglise, C., Oeser, B., Pearson, M., Poulain, J., Poussereau, N. Quesneville, H., Rascale, C., Schumacher, J., Ségurens, B., Sexton, A., Silva, E., Sirven, C., Soanes, D. M., Talbot, N. J., Templeton, M., Yandava, C., Yarden, O., Zeng, Q. D., Rollins, J. A., Lebrun, M.-H., and Dickman, M. 2011. Genomic analysis of the necrotrophic fungal pathogens Sclerotinia sclerotiorum and Botrytis cinerea. PLoS Genet. 7:e1002230.

Anderson, J. B., and Kohn, L. M. 1995. Clonality in soilborne plant-pathogenic fungi. Annu. Rev. Phytopathol. 33:369-391.

Atallah, Z. K., Larget, B., Chen, X., and Johnson, D. A. 2004. High genetic diversity, phenotypic uniformity, and evidence of outcrossing in Sclerotinia sclerotiorum in the Columbia Basin of Washington State. Phytopathology 94: 737-742. 
Attanayake, R. N., Carter, P. A., Jiang, D. H., Río-Mendoza, L., and Chen, W. 2013. Sclerotinia sclerotiorum populations infecting canola from China and the United States are genetically and phenotypically distinct. Phytopathology 103:750-761.

Attanayake, R. N., Porter, L., Johnson, D. A., and Chen, W. 2012. Genetic and phenotypic diversity and random association of DNA markers of isolates of the fungal plant pathogen Sclerotinia sclerotiorum from soil on a fine geographical scale. Soil Biol. Biochem. 55:28-36.

Attanayake, R. N., Tennekoon, V., Johnson, D. A., Porter, L. D., del Rio-Mendoza, L., Jiang, D. H., and Chen, W. 2014. Inferring outcrossing in the homothallic fungus Sclerotinia sclerotiorum using linkage disequilibrium decay. Heredity 113:353-363.

Barari, H., Alavi, V., and Badalyan, S. M. 2010. Genetic and morphological diversities in Sclerotinia sclerotiorum isolates in northern parts of Iran. World Appl. Sci. J. 8:326-333.

Bolton, M. D., Thomma, P. H. J., and Nelson, B. D. 2006. Sclerotinia sclerotiorum (Lib.) de Bary: biology and molecular traits of a cosmopolitan pathogen. Mol. Plant Pathol. 7:1-16.

Carpenter, M. A., Frampton, C., and Stewart, A. 1999. Genetic variation in New Zealand populations of the plant pathogen Sclerotinia sclerotiorum. N. Z. J. Crop Hortic. Sci. 27:13-21.

Chitrampalam, P., Inderbitzin, P., Maruthachalam, K., Wu, B. M., and Subbarao, K. V. 2013. The Sclerotinia sclerotiorum mating type locus (MAT) contains a $3.6-\mathrm{kb}$ region that is inverted in every meiotic generation. PLoS One 8: e56895.

Chitrampalam, P., and Pryor, B. M. 2015. Characterization of mating type (MAT) alleles differentiated by a natural inversion in Sclerotinia minor. Plant Pathol. 64:911-920.

Clarkson, J. P., Coventry, E., Kitchen, J., Carter, H. E., and Whipps, J. M. 2013. Population structure of Sclerotinia sclerotiorum in crop and wild hosts in the UK. Plant Pathol. 62:309-324.

Cubeta, M. A., Sermons, D. N., and Cody, B. R. 2001. Mycelial interactions of Sclerotinia minor. Phytopathology 91:S19.

Durman, S. B., Menéndez, A. B., and Godeas, A. M. 2003. Mycelial compatibility groups in Buenos Aires field populations of Sclerotinia sclerotiorum (Sclerotiniaceae). Aust. J. Bot. 51:421-427.

Ekins, M., Aitken, E. A., and Coulter, K. C. 2006. Homothallism in Sclerotinia minor. Mycol. Res. 110:1193-1199.

Ekins, M., Aitken, E. A. B., and Coulter, K. C. 2002. Carpogenic germination of Sclerotinia minor and potential distribution in Australia. Australas. Plant Pathol. 31:259-265.

Garrido, P. A., Dobhal, S., Flores, F. J., Rodriguez, C. G., Blough, K., Melouk, H., and Garzon, C. D. 2011. Population structure and genetic diversity of Sclerotinia minor from peanut research plots in Oklahoma. Phytopathology 101:S59.

Hawthorne, B. T. 1976. Observation on the development of apothecia of Sclerotinia minor Jagg. in the field. N. Z. J. Agric. Res. 19:383-386.

Hemmati, R., Javan-Nikkhah, M., and Linde, C. C. 2009. Population of Sclerotinia sclerotiorum on canola in Iran. Eur. J. Plant Pathol. 125:617-628.

Hollowell, J. E., Shew, B. B., Cubeta, M. A., and Wilcut, J. W. 2003. Weed species as hosts of Sclerotinia minor in peanut fields. Plant Dis. 87:197-199.

Huang, H. C., and Dueck, J. 1980. Wilt of sunflower from infection by myceliagerminating sclerotia of Sclerotinia sclerotiorum. Can. J. Plant Pathol. 2:47-52.

Kohli, Y., and Kohn, L. M. 1996. Mitochondrial haplotypes in populations of the plant-infecting fungus Sclerotinia sclerotiorum: wide distribution in agriculture, local distribution in the wild. Mol. Ecol. 5:773-783.
Kohn, L. M., Stasovski, E., Carbone, I., Royer, J., and Anderson, J. B. 1991. Mycelial incompability and molecular markers identify genetic variability in field populations of Sclerotinia sclerotiorum. Phytopathology 81:480-485.

Lehner, M. S., Paula Júnior, T. J., Hora Júnior, B. T., Teixeira, H., Vieira, R. F., Carneiro, J. E. S., and Mizubuti, E. S. G. 2015. Low genetic variability in Sclerotinia sclerotiorum populations from common bean fields in Minas Gerais State, Brazil, at regional, local and micro-scales. Plant Pathol. 64:921-931.

Li, G. Q., Wang, D. B., Qiou, X. Y., and Jiang, D. H. 1994. Analysis on the pathogens of lettuce drop in Hubei province. J. Huazhong Agric. Univ. 13:250-253.

Li, M., Wang, K., Zhang, Y. Y., Hou, Y. G., Chen, W. D., Zhou, H. Y., and Zhao, J. 2016. First report of sunflower white mold caused by Sclerotinia minor Jagger in Inner Mongolia region, China. Plant Dis. 100:211.

Li, Z., Wang, Y., Chen, Y., Zhang, J., and Fernando, W. G. D. 2009. Genetic diversity and differentiation of Sclerotinia sclerotiorum populations in sunflower. Phytoparasitica 37:77-85

Lyu, A., Zhang, J., Yang, L., and Li, G. Q. 2014. First report of Sclerotinia minor on Brassica rapa subsp. pekinensis in central China. Plant Dis. 98:992.

Mandal, A. K., and Dubey, S. C. 2012. Genetic diversity analysis of Sclerotinia sclerotiorum causing stem rot in chickpea using RAPD, ITS-RFLP, ITS sequencing and mycelial compatibility grouping. World J. Microbiol. Biotechnol. 28:1849-1855.

Melzer, M. S., and Boland, G. J. 1996. Transmissible hypovirulence in Sclerotinia minor. Can. J. Plant Pathol. 18:19-28.

Melzer, M. S., Smith, E. A., and Boland, G. J. 1997. Index of plant hosts of Sclerotinia minor. Can. J. Plant Pathol. 19:272-280.

Möller, E. M., Bahnweg, G., Sandermann, H., and Geige, H. H. 1992. A simple and efficient protocol for isolation of high molecular weight DNA from filamentous fungi, fruit bodies, and infected plant tissues. Nucleic Acids Res. 20:6115-6116.

Sexton, A. C., and Howlett, B. J. 2004. Microsatellite markers reveal genetic differentiation among populations of Sclerotinia sclerotiorum from Australian canola fields. Curr. Genet. 46:357-365.

Sexton, A. C., Whitten, A. R., and Howlett, B. J. 2006. Population structure of Sclerotinia sclerotiorum in an Australian canola field at flowering and steminfection stages of the disease cycle. Genome 49:1408-1415.

Sirjusingh, C., and Kohn, L. M. 2001. Characterization of microsatellites in the fungal plant pathogen, Sclerotinia sclerotiorum. Mol. Ecol. Notes 1:267-269.

Subbarao, K. V. 1998. Progress toward integrated management of lettuce drop. Plant Dis. 82:1068-1078.

Wen, A. Q., Zhou, J. W., and Zhou, H. P. 1995. Control measures for sunflower Sclerotinia minor diseases. J. Inner Mongolia Inst. Agric. Anim. Husb. 16: $56-59$.

White, T. J., Bruns, T., Lee, S., and Taylor, J. 1990. Amplification and direct sequencing of fungal ribosomal RNA genes for phylogenetics. Pages 315-322 in: PCR protocols: a guide to methods and applications. M. A. Innis, D. H Gelfand, J. J. Sninsky, and T. J. White, eds. Academic Press, San Diego.

Wu, B. M., and Subbarao, K. V. 2001. Mycelium compatibility grouping of Sclerotinia minor populations from lettuce in central California. Phytopathology 91:S96.

Wu, B. M., and Subbarao, K. V. 2006. Analyses of lettuce drop incidence and population structure of Sclerotinia sclerotiorum and S. minor. Phytopathology 96:1322-1329.

Wu, M. D., Zhang, L., Li, G. Q., Jiang, D. H., Hou, M. S., and Huang, H.-C. 2007. Hypovirulence and double-stranded RNA in Botrytis cinerea. Phytopathology 97:1590-1599. 